Rare morph Lake Malawi mbuna cichlids benefit from reduced aggression from con- and hetero-specifics

Tyers, Alexandra M.; Cooke, Gavan M.; Turner, George F.

\title{
Journal of Evolutionary Biology
}

DOI:

10.1111/jeb.13929

Published: 01/11/2021

Publisher's PDF, also known as Version of record

Cyswllt i'r cyhoeddiad / Link to publication

Dyfyniad o'r fersiwn a gyhoeddwyd / Citation for published version (APA):

Tyers, A. M., Cooke, G. M., \& Turner, G. F. (2021). Rare morph Lake Malawi mbuna cichlids benefit from reduced aggression from con- and hetero-specifics. Journal of Evolutionary Biology, 34(11), 1678-1690. https://doi.org/10.1111/jeb.13929

\footnotetext{
Hawliau Cyffredinol / General rights

Copyright and moral rights for the publications made accessible in the public portal are retained by the authors and/or other copyright owners and it is a condition of accessing publications that users recognise and abide by the legal requirements associated with these rights. study or research.

download and print one copy of any publication from the public portal for the purpose of private

- You may not further distribute the material or use it for any profit-making activity or commercial gain

- You may freely distribute the URL identifying the publication in the public portal ?
}

Take down policy

If you believe that this document breaches copyright please contact us providing details, and we will remove access to the work immediately and investigate your claim. 


\title{
Rare morph Lake Malawi mbuna cichlids benefit from reduced aggression from con- and hetero-specifics
}

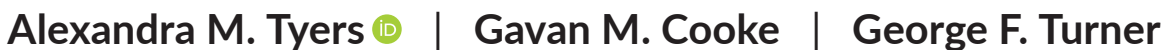

School of Biological Sciences, Bangor University, Bangor, UK

Correspondence and present address Alexandra M. Tyers, Max Planck Institute for Biology of Ageing, Joseph-StelzmannStraße, 9B 50931 Cologne, Germany. Email: alexandra.m.tyers@gmail.com

Funding information

Bangor University

\begin{abstract}
Balancing selection is important for the maintenance of polymorphism as it can prevent either fixation of one morph through directional selection or genetic drift, or speciation by disruptive selection. Polychromatism, the presence of multiple genetically determined colour phenotypes, can be maintained if the fitness of alternative morphs depends on the relative frequency in a population. In aggressive species, negative frequency-dependent antagonism can prevent an increase in the frequency of rare morphs as they would only benefit from increased fitness while they are rare. Heterospecific aggression is common in nature and has the potential to contribute to rare morph advantage. Here we carry out field observations and laboratory aggression experiments with mbuna cichlids from Lake Malawi, to investigate the role of con- and heterospecific aggression in the maintenance of polychromatism and identify benefits to rare morphs which are likely to result from reduced aggression. We hypothesize that rare morph individuals receive less aggression than common morph individuals and therefore have an ecological advantage. Within species we found that males and females bias aggression towards their own morph, adding to the evidence that inherent own-morph aggression biases can contribute to balancing selection. Over-representation of rare morph territory owners may be influenced by two factors; higher tolerance of different morph individuals as neighbours, and the ability of rare morphs to spend more time feeding. Reduced aggression to rare morph individuals by heterospecifics may also contribute to rare morph advantage.
\end{abstract}

KEYWORDS

aggression, blotch polymorphism, cichlid, Malawi, rare morph advantage

\section{1 | INTRODUCTION}

Permanent polymorphism, the presence of multiple genetically determined morphological or behavioural phenotypes within a population, is common in nature and indicates some type of selective balance between morphs. Balancing selection is important for the maintenance of polymorphism as it can prevent either fixation of one morph through directional selection or genetic drift, or speciation by disruptive selection (Huxley, 1955; Kim et al., 2019; Wellenreuther et al., 2014). Like other polymorphisms, polychromatism (colour polymorphism) can be maintained if the fitness of alternative morphs differs in time or space in heterogeneous environments, or 
if the fitness of a phenotype depends on its relative frequency in a population (Henze et al., 2018; Hughes et al., 2013; Pérez i de Lanuza et al., 2017; Surmacki et al., 2013; Svensson, 2017).

In many taxa, species-recognition cues have diverged through reproductive or antagonistic character displacement to reduce hybridization or unnecessary exertion and risk of injury among heterospecifics which are not in direct competition for mates or resources (Grether et al., 2009; Seehausen \& Schluter, 2004). Rare colour morphs can benefit from lack of recognition by receiving less matingrelated harassment (Takahashi et al., 2010) or less intrasexual aggression from conspecifics (Dijkstra et al., 2008; Lehtonen, 2014; Pérez i de Lanuza et al., 2017; Scali et al., 2020). In aggressive species, negative frequency-dependent antagonism, generated through either evolution of an own-morph bias (Dijkstra et al., 2008; Lehtonen, 2014; Scali et al., 2020) or by a dynamic common morph bias based on experience (Bolnick et al., 2016), can prevent an increase in the frequency of rare morphs as they would only benefit from increased fitness (due to reduced aggression) while they are rare (Bolnick et al., 2016; Dijkstra et al., 2007; Seehausen \& Schluter, 2004).

The existence of conspecific aggression biases does not preclude heterospecific aggression completely. Indeed, recent studies suggest that heterospecific aggression as a result of resource competition and reproductive interference may be more common than previously assumed (Drury et al., 2020; Grether et al., 2009). Regardless of whether heterospecific aggression is due to convergence in territorial signals among species competing for resources or due to misdirection of aggression because closely related species still share similar signals (Losin et al., 2016), in a variety of taxa aggression is often higher among more similar coloured than more differently coloured species (Anderson \& Grether, 2010; Genner et al., 1999; Losin et al., 2016; Pauers et al., 2008). In taxa, where multiple ecologically and phenotypically similar species co-exist in the same habitat there is therefore potential for rare morphs to benefit not only from reduced conspecific aggression, but also from reduced heterospecific aggression. A recent study of Midas cichlids, however, demonstrated increased aggression towards rare heterospecific morphs and suggested that this disadvantage may help to explain their lower frequency in natural populations (Lehtonen et al., 2015). The role of heterospecific aggression in relation to polychromatism requires further exploration to improve our understanding of how this may contribute to its evolution and maintenance.

The mbuna cichlids of Lake Malawi (and the closely related ecologically similar Mbipi of Lake Victoria) provide an excellent system for the investigation of colour polymorphism. Mbuna inhabit densely packed multi-species communities in the shallow-waters and identify conspecific mates and rivals predominantly by their species-specific colour and pattern (e.g. Couldridge \& Alexander, 2002; Seehausen \& van Alphen, 1998; Jordan, 2008; Pauers et al., 2008). Several species display a polychromatism characterized by the presence of rare 'blotched' morph individuals, which occur at different frequencies in different species and populations (Konings, 2007; Lande et al., 2001; Ribbink et al., 1983). While it is likely that differences in conspicuousness among morphs (resulting in differences in the likelihood predation) has played some role in the evolution of this polychromatism (Maan et al., 2008; Roberts et al., 2009; Seehausen et al., 1999; Streelman et al., 2003), and mate choice may have been involved in the evolution of (partial) sex-linkage (Lande et al., 2001; Roberts et al., 2009; Seehausen et al., 1999), it is thought that intrasexual competition plays a large role in its maintenance (Dijkstra et al., 2008; Dijkstra, van Dijk, et al., 2009). Although in most species the frequency of rare morphs remains relatively low in all populations, in some, for example, Maylandia callainos at Thumbi West Island in Lake Malawi, rare morphs can occur with higher frequency, which allows greater ease of observation and collection. Here we used this population, which consists of a common blue and a rare white morph, to conduct field observations and laboratory behavioural experiments to test alternative hypotheses regarding aggression biases: Do both morphs preferentially direct aggression towards the common (presumably ancestral) blue morph, or is there an own-morph bias? An own-morph bias could be sufficient to maintain polymorphism through negative frequency-dependent selection because the advantage to the rare morph would be reduced as it becomes more common. A common/blue-morph bias, however, would result in continuous advantage to the rare/white-morph through reduced aggression even as it became more common. In the case of common-morph aggression bias an additional frequency-dependent process, or another factor resulting in lower survival/reproduction of the rare morph, would therefore be necessary to limit an increase in the number of rare morph individuals. We also test for aggression biases towards the common and rare morph from a closely related heterospecific (Maylandia zebra) to assess whether this may contribute to balancing selection. We aim to identify potential benefits to rare morphs, which may occur as a result of receiving less aggression, in the natural environment. Additionally, as differences in selection pressures on each sex, due to differences in the type of competition they experience (competition for mates among males and competition for non-mating resources among females) can result in sex differences in the types of aggressive behaviour used during contests (Arnott \& Elwood, 2009), we also test for sex-differences in aggressive behaviour and aggression biases.

\section{2 | METHODS}

\section{1 | Study system}

Maylandia callainos (=Pseudotropheus callainos or Metriaclima callainos) is a member of the 'mbuna' complex of rocky shore cichlid fishes endemic to Lake Malawi. Populations of M. callainos are found in shallow water, with peak population density between 3 and $10 \mathrm{~m}$ (full range $0-25 \mathrm{~m}$ ). Their natural range is confined to the northern end of Lake Malawi, where they are often found in sympatry with the more widely distributed ecologically similar congeneric M. zebra. However, due to human-mediated translocations, they are also found in some southern areas. Phenotypes of common and rare morph mbuna differ between species, but within populations, 
the common morph is often BB (black vertical melanin bars on a blue/dark background) or solid blue/dark body colour, while rarer morphs have a disrupted melanin pattern of many or few blotches/ spots on a light (orange/pink/white) body. Blotch polychromatism is not present in all M. callainos and M. zebra populations; at some localities only the plain blue (B) and BB morph are found, whereas at others, these common morphs may occur along side rare white (W) and orange-blotch $(\mathrm{OB})$ and very rare white-blotch and orange $(\mathrm{O})$ morphs. In this study we focus on a well-established translocated population of M. callainos at Thumbi West Island in the Lake Malawi National Park in the southwest arm of the lake which has both $B$ and W morph fish (Figure 1a). The likely source population of the M. callainos at Thumbi West is Nkhata Bay, where they co-occur with a population of M. zebra comprised $\mathrm{BB}, \mathrm{OB}$ and $\mathrm{O}$ morph individuals.

All fish were wild caught: M. callainos and M. zebra from Thumbi West Island (TW) in July 2010, M. zebra from Nkhata Bay (NB) and Chiofu Bay (CB-naïve to M. callainos in the wild and lab) in 2009. Males and females were used in this study (Figure 1c), partially because of the lower number of rare males, but also because both male and female aggression biases have previously been suggested to be important in colour polymorphism maintenance in cichlids (e.g. Dijkstra et al., 2008). Furthermore, unlike many species with blotch polychromatism, this one is less strongly female limited, as numerous white M. callainos males were found at the study/collection site.

\section{2 | Field observations (excluding aggression)}

\subsection{1 | Frequency of blue and white morph} M. callainos at Thumbi West Island

Snorkel observations were used to estimate the ratio of $\mathrm{B}$ to $\mathrm{W}$ M. callainos morphs in the general population. Dominant mature adult males can be easily recognized by their behaviour and colour, but females and immature males are indistinguishable and are referred to as 'apparent females'. Hence, the number of males and apparent females of each morph was counted along three $30 \mathrm{~m}$ transects covering an area half a meter each side of the line ( $n=74$ fish). The numbers of territory-holding males of each morph were counted in nine $5 \mathrm{~m}^{2}$ quadrats ( $n=142 \mathrm{fish}$ ). Although ideally, the comparison should be made between non-territorial males and territorial males, in practice this was not possible due to the difficulty in sexing fish without catching them. However, it is likely that in the whole population, rare morph males occur at a lower frequency than rare morph females (as found in other closely related species with blotch polychromatism, Lande et al., 2001; Maan \& Sefc, 2013), which would make estimates of the ratio of rare to common morph males among non-territorial fish a conservative estimate; territorial $W$ males would be present at a much lower frequency than predicted from the ratio of $\mathrm{W}$ morph in the general population.

\subsection{2 | Territory distances between morphs}

Territory maps were constructed by drawing the rocky substrate, within $5 \times 5 \mathrm{~m}$ string quadrats $(n=9)$, on dive slates while snorkelling. Males frequently return to their spawning cave and focal observations allowed for accurate determination of the position of this territorial focal point for each male within the quadrats. The distance between the territory focal point of each male within the centre $3 \mathrm{~m}^{2}$ ( $n=27 \mathrm{~B} \& 25 \mathrm{~W}$ ) and closest white and blue neighbour (including fish nearer the edge of the quadrat) was then measured.

\subsection{3 | Grazing differences between morphs}

Each grazing action performed by focal individuals was recorded during 10-min observations of territorial males and non-territorial fish ( $n=9$ individuals of each morph for each social status). (a)

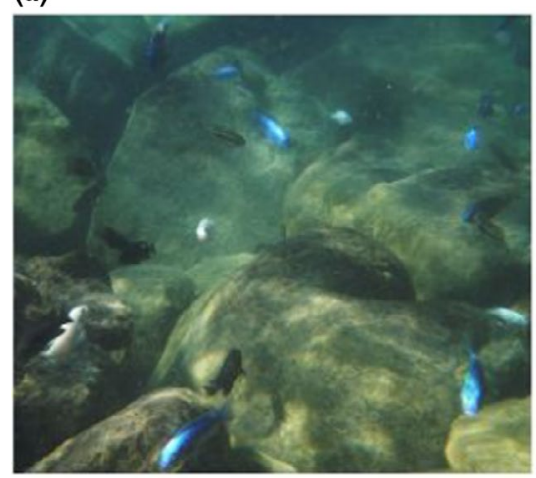

(b)

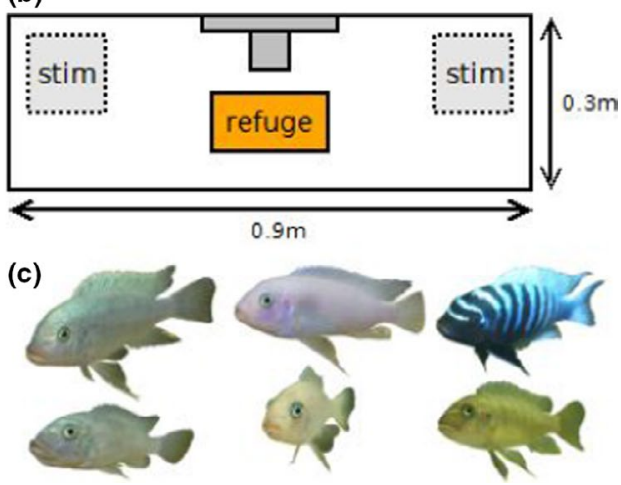

FIGURE 1 Study system and methods. (a) Mbuna community at Thumbi West Island, showing blue (B) and white (W) morph Maylandia callainos. (b) Plan view of experimental tank for pairwise intruder choice aggression trials in the lab: refuge $=$ cave made from three bricks to act as the territorial focal point/refuge for the focal fish; stim = perforated plastic jars to hold the two stimulus fish; position of the tank heater and filter indicated by dark grey boxes. (c) Male (top) and female (bottom) of B (left) and W (middle) morph M. callainos and BB morph M. zebra (right) 


\subsection{Field observations of aggressive interactions}

During focal observation lasting 10 min per fish $(n=9$ territorial males of each morph) all aggressive behaviours directed towards the two conspecific morphs were recorded. The vast majority of all aggressive acts recorded were 'chases', lateral displays were observed but rare, counts of each type of behaviour were summed for analysis. While collecting data on conspecific aggression biases, aggression towards each focal fish from heterospecifics was also recorded.

\section{4 | Laboratory aggression trials}

To test whether there are differences in the level aggression received by blue and white morph M. callainos from conspecifics and heterospecifics, three experiments were carried out using the same methods. Five minute pairwise aggression trials were conducted in two replicate tanks measuring $0.9 \times 0.3 \times 0.3 \mathrm{~m}$. Each tank contained a central brick refuge to act as a territory focal point, two transparent (perforated) plastic jars to hold the stimulus fish, an air-driven box filter and an internal heater to maintain the water temperature at ca. $22-24^{\circ} \mathrm{C}$ (Figure $\left.1 \mathrm{~b}\right)$. Lights were kept on a 12:12 light:dark cycle. All fish were fed flake food once a day. Females and males were used but stimulus fish were always the same sex as focal fish. Focal fish were allowed at least $24 \mathrm{~h}$ to acclimatize before the introduction of the stimuli and recording of focal fish behaviour began after emergence from the central refuge. Individual aggressive behaviours (frontal/lateral display, quiver, lunge/butt and bite) were recorded and combined to give an overall aggression count for each individual. To control for potential tank side bias, two separate trials were carried out with each focal fish, each with a different stimulus fish pair and with morphs swapped between sides. To avoid pseudoreplication from the re-use of focal males, before analysis an average was taken of the aggressive behaviour observed in the two trials by each individual.

\subsection{1 | Exp. 1: Interspecific aggression biases between species}

Firstly, conspecific aggression bias was confirmed by presenting BB M. zebra males from CB $(n=10)$ with pairs of conspecific BB and heterospecific $B$ stimulus fish.

\subsubsection{Exp. 2: Intraspecific aggression biases between morphs}

For this experiment all available M. callainos were used as focal and stimulus fish ( $n=10$ B male, six B female, three $W$ male and nine $W$ female) to test for morph-specific aggression biases among conspecifics.

\subsection{3 | Exp. 3: Interspecifc aggression to different morphs}

BB M. zebra focal fish from different populations $(n=12$ male/ 12 female 'TW', 12 male/5 female 'NB', 12 male/12 female 'CB') were used to test for heterospecific aggression biases to $B$ and $W$ M. callainos stimulus pairs. Stimulus pairs consisted of the same M. callainos used in Exp. 2.

\subsection{Data analysis}

Statistical analysis was carried out using RStudio (v. 1.2.5033; RStudio Team, 2019) with additional packages: MASS (for negative binomial models), Ime4 (for mixed effects models), performance (for checking overdispersion of generalized linear models) and ggplot2 (for plotting). General and generalized linear models were used with different distributions (and canonical link functions) depending on the type of data: Gaussian distribution for analysis of continuous data (territory distances), Poisson or negative binomial models for data where the response variable is a single count (grazing frequency, total aggression counts and aggression received from heterospecifics in the field), binomial or quasibinomial distributions for count data resulting from a binary choice (aggression towards different morphs in the field and in pairwise laboratory aggression trials, and also the ratio of attacks:displays)-further details of model specifications for each analysis are given below. Summary statistics and significance values are reported from $t$-test for general linear models and z-test for generalized linear models. One M. zebra female in Exp.3 (Interspecific aggression to different morphs) only left the central refuge briefly at the start of the trial, this fish was excluded from the analysis due to lack of territoriality/interaction with the stimuli fish.

\subsection{1 | Frequency of blue and white morphs at Thumbi West Island}

A G-test was used to compare the actual number of territory holding white (W) males observed with what would be expected given the proportions of blue (B) and $\mathrm{W}$ morphs in the general population.

\subsection{2 | Territory distances between morphs}

General linear models (Table 1a) were used to test for the effect of neighbour morph type on the average distance (in meters) between the territory focal points of: (i) each territory holding male and the nearest same and different morph neighbour. (ii) each $B$ male and the nearest $B$ and $W$ neighbour, (iii) each $W$ male and the nearest $B$ and $\mathrm{W}$ neighbour. 
TAB LE 1 Model construction for analysis of: (a) Differences in territory distances among Maylandia callainos morphs (results Table 2).

(b) Differences in grazing frequency between morphs (results Table 3). (c) Aggression biases by and towards M. callainos morphs in the field (results Table 4). (d) Differences in total aggression displayed by the different species, populations and sexes in laboratory aggression trials (results Table 5). (e) Aggression biases in pairwise intruder choice tests in the laboratory (results Table 6)

$\begin{array}{lllll}\text { Model Distribution } & \text { Link } & \begin{array}{l}\text { Response variable (and } \\ \text { sample size) }\end{array} & \text { Fixed factors } & \text { Random } \\ \text { effect }\end{array}$

(a) Territory distances between morphs

iii)

Gaussian

Identity

Identity

Gaussian

Gaussian

Identity

(b) Grazing differences between morphs

(c) Field observations of aggressive behaviour

i) Binomial Logit

ii) Binomial Logit

iii) Binomial Logit

iv) Binomial Logit

v) Poisson Log

(d) Laboratory aggression trials: Aggression levels

i) Negative binomial Logit

ii) Negative binomial Logit

iii) Quasibinomial Logit

iv) Negative binomial Logit
Distance $(m)$ from all fish

$$
(n=52)
$$

Distance $(m)$ from $B$ fish

$$
(n=27)
$$

Distance $(\mathrm{m})$ from $\mathrm{W}$ fish

$$
(n=25)
$$

Grazing count ( $n=36$ fish)

Status (territorial or not) + Morph (B or W)

Aggression count: All focals

$$
(n=18)
$$

Aggression count: All focals

$$
(n=18)
$$

Aggression count: B focals

$$
(n=9)
$$

Aggression count: $W$ focals

$$
(n=9)
$$

Aggression received from heterospecifics ( $n=18$ focal fish)

Morph of neighbour (same or different)

Morph of neighbour (B or W)

Morph of neighbour (B or W)

Morph of focal fish (B or W)
Morph of aggressed intruder $(\mathrm{B} \text { or } \mathrm{W})^{*}$ Focal $\quad$ Focal ID
Morph $(\mathrm{B}$ or $\mathrm{W})$

Morph of aggressed intruder (B or W) Focal ID

Morph of aggressed intruder (B or W) Focal ID

Morph of aggressed intruder (B or W) Focal ID

Aggression count: all focal Species (M.cal or M.zeb) + Sex (female or male) fish $(n=103)$

Aggression count: male $\quad \operatorname{Exp}(1,2,3)$ subset $(n=35)$

Attack:Display: Exp 2\&3 Species (M.cal or M.zeb) + Sex (female or male) focals $(n=92)$

Total aggression count: M.zeb Population (CB, NB, TW) + Sex (female or male) $(n=65)$

(e) Laboratory aggression trials: Aggression biases

Exp 1; BB focal fish, conspecific/heterospecific stimulus fish
i)
Quasibinomial
Logit
Aggression count: BB males
Stimulus morph (BB or B) $(n=10)$

Exp 2; B\&W focal fish, conspecific stimulus fish
ii) Quasibinomial
Logit
iii) Quasibinomial Logit

Aggression count: B\&W focals $(n=28)$

Aggression count: B\&W focals $(n=28)$

Focal morph $(\mathrm{B}$ or $\mathrm{W}){ }^{*}$ Stimulus morph (B or $W)+$ Sex (female or male)

Stimulus morph (own or other) + Stimulus morph (common or rare)

Exp 3; BB focal fish, heterospecific stimulus fish
iv) Quasibinomial Logit
v) Quasibinomial Logit

Aggression count: BB focals $(n=64)$

Aggression count to $\mathrm{B}$ : $\mathrm{BB}$ focals $(n=64)$

Abbreviations: CB, Chiofu Bay; M.cal, M. callainos (B, blue morph; M.zeb, M. zebra (BB, blue/black/barred morph);NB, Nkhata Bay; TW, Thumbi West Island; W, white morph). 

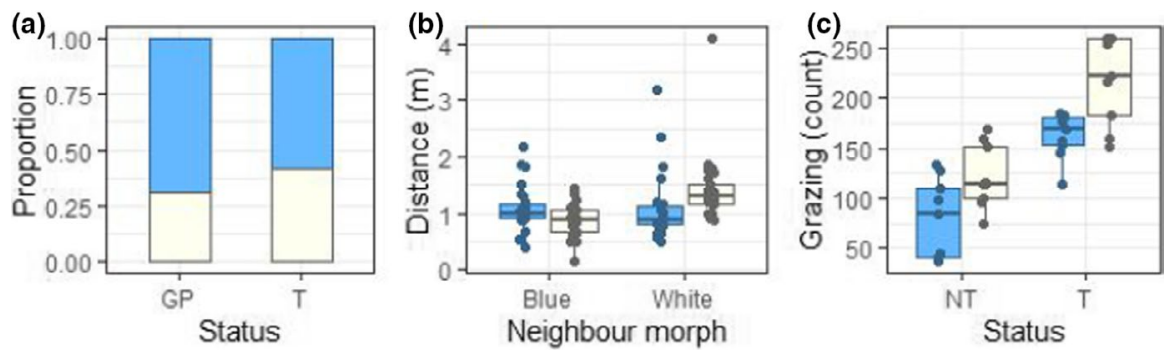

FIGURE 2 Field observations of behavioural differences among Maylandia callainos colour morphs at Thumbi West Island. Bar colour $=$ focal fish colour. (a) There are significantly more territory holding $(T)$ white males than would be expected given the proportion of each morph in the general population (GP; see text for details). (b) Males of the same morph hold territories at a significantly greater distance from each other than different morph males (Table 2). (c) W morph fish graze significantly more than B morph fish regardless of social status (Table 3). NT, non-territorial; T, territorial

\subsection{3 | Grazing differences between morphs}

A generalized linear model was used to test for the effect of dominance status and morph/colour on grazing frequency in the field. Due to the overdispersion of the initial Poisson regression model, a negative-binomial model was chosen (Table 1b).

\subsection{4 | Field observations of aggressive behaviour}

Generalized linear models (Table 1c) were used to test for aggression biases by and towards the M. callainos morphs in the field. Aggression directed towards territorial intruders of each of the two colour morphs was recorded and mixed effect binomial models (with focal fish ID included as a random factor) were used to test: (i) the effect of an interaction between focal and intruder colour (morph) on the aggression count, (ii) the effect of intruder colour on the amount of aggression received (regardless of focal fish morph), (iii) the effect of intruder colour on the amount of aggression received from territorial B males, and (iv) the effect of intruder colour on the amount of aggression received from territorial $\mathrm{W}$ males. Poisson regression was used to test for $(v)$ the effect of M. callainos territorial male colour on the amount of aggression received from heterospecific fish.

\subsection{5 | Laboratory aggression trials}

Generalized linear models (Table 1d) were used to test for the effects of species, population and sex on the level of aggression (total aggression count to both stimulus fish) recorded in pairwise intruder choice experiments. As initial Poisson regression models were all overdispersed, other models suitable for analysis of overdispersed count data were compared: Negative binomial models resulted in lower dispersion ratio, larger standard error and more conservative $p$-values than quasipoisson models and were therefore chosen to test: (i) all data for the effect of species and sex on level of aggression, (ii) a subset of males for the effect of species on the level of aggression. A quasibinomial model was used to test for (iii) the effect of species and sex on the ratio of attacks:displays. And finally, a negative binomial model was used to test for (iv) the effect of population and sex on the level of aggression displayed by M. zebra focal fish when presented with pairs of B and W M. callainos stimulus fish.

Generalized linear models were also used to test for aggression biases in the pairwise intruder choice experiments. Two statistical approaches were compared: Binomial mixed effect models with 'focal ID' as a random effect (data included aggression count from each focal fish to each of the two stimulus types) were overdispersed and the random effect variance was always zero (see Table $\mathrm{S} 1$ for the results of these models). The random effect was therefore omitted in order to use quasibinomial models (which are suitable for analysis of overdispersed count data and gave larger standard errors and more conservative $p$-values-Table 1e) to (i) confirm that conspecific aggression biases could be detected in this experimental set-up, (ii) test for an interaction between focal and stimulus morph on the aggression from M. callainos focal fish to different morph conspecifics, (iii) check for common-morph or own-morph aggression bias in M. callainos, (iv) test whether M. callainos stimulus fish colour has an effect on the amount of aggression received from M. zebra and ( $v$ ) test whether M. zebra population has an effect on the aggression bias (depending on whether they co-occur with M. callainos or not).

\section{3 | RESULTS}

\subsection{Field observations (excluding aggression)}

\subsection{1 | Frequency of the blue and white morphs at} Thumbi West Island

There were significantly more territory holding rare $\mathrm{W}$ morph males than would be expected given the proportion of $W$ and $B$ morph fish in the general population (Territorial $B=83, W=59$; General population $B=51, W=23$. $G$-test: $G_{1}=6.91, p=0.009$; Figure $2 a$ ).

\subsection{2 | Territory distances between morphs}

First, whether a neighbour is of the same or different morph has a significant effect on the territory distance between males 
TAB LE 2 Descriptive statistics and full general linear model results for differences in territory distances between Maylandia callainos morphs ( $\mathrm{B}=$ blue, $\mathrm{W}$ = white). Roman numerals correspond to those given in methods (Table $1 \mathrm{a}$ )

\begin{tabular}{|c|c|c|c|c|c|c|c|}
\hline Model & $\begin{array}{l}\text { Response } \\
\text { variable }\end{array}$ & Fixed factor ( $\&$ mean) & $d f$ & Estimate & SE & $t$-value & $p$-value \\
\hline i) & Distance from all & Intercept & 103 & 0.98 & 0.07 & 13.81 & $<0.001$ \\
\hline \multirow[t]{2}{*}{ ii) } & \multirow[t]{2}{*}{ Distance from B } & Intercept & \multirow[t]{2}{*}{53} & 1.07 & 0.10 & 11.14 & $<0.001$ \\
\hline & & Neighbour morph $(B=1.07 \mathrm{~m}, \mathrm{~W}=1.07 \mathrm{~m})$ & & 0.00 & 0.14 & -0.01 & 0.994 \\
\hline iii) & Distance from $\mathrm{W}$ & Neighbour morph $(B=0.89 \mathrm{~m}, \mathrm{~W}=1.40 \mathrm{~m})$ & 49 & 0.52 & 0.14 & 3.73 & $<0.001$ \\
\hline
\end{tabular}

Abbreviations: $d f$, Degrees of freedom; SE, standard error (Figure $2 b$ ).

TAB LE 3 Descriptive statistics and generalized linear model results for differences in grazing frequency between Maylandia callainos morphs (B, blue; $\mathrm{W}$, white). Roman numerals correspond to those given in methods (Table $1 \mathrm{~b}$ )

\begin{tabular}{|c|c|c|c|c|c|c|c|c|}
\hline Model & $\begin{array}{l}\text { Response } \\
\text { variable }\end{array}$ & Fixed factor (and means) & $d f$ & Estimate & SE & $z$-value & $p$-value & DR \\
\hline i) & Grazing count & $\begin{array}{l}\text { Intercept } \\
\text { Status (territorial = 190, } \\
\quad \text { non-territorial = 100) } \\
\text { Morph }(B=120, W=170)\end{array}$ & 35 & $\begin{array}{l}4.40 \\
0.65 \\
0.36\end{array}$ & $\begin{array}{l}0.09 \\
0.10 \\
0.10\end{array}$ & $\begin{array}{l}51.06 \\
6.67 \\
3.69\end{array}$ & $\begin{array}{l}<0.001 \\
<0.001 \\
<0.001\end{array}$ & 12.7 \\
\hline
\end{tabular}

Abbreviations: $d f$, degrees of freedom; DR, dispersion ratio; SE, standard error (Figure 2c).

( $p=0.014-$ Table 2 model i): On average, territorial males of the same morph are found at a greater distance from each other than territorial males of different morphs. While it is not surprising to find that $\mathrm{W}$ and $\mathrm{W}$ are found furthest apart, as this would be the assumption based on the observation of a lower frequency of $\mathrm{W}$ morph territorial males, if the distance between morphs was only based on frequency, it would also be expected that the distance between $B$ morph males should on average be the smallest distance. This is not the case: The distance between $B$ and nearest $B$ is on average the same as, and not significantly different from, the distance between $\mathrm{B}$ and nearest $\mathrm{W}$ ( $p=0.994-T a b l e ~ 2$ model ii). We also found that the distance between $\mathrm{W}$ males and their nearest $\mathrm{B}$ neighbour is on average the smallest distance recorded between territorial males, and significantly different from the distance between $\mathrm{W}$ territorial males and their nearest $\mathrm{W}$ neighbour ( $p<0.001-$ Table 2 model iii; Figure $2 b$ ).

\subsection{3 | Grazing differences between morphs}

Both dominance status and morph colour had a significant effect on grazing frequency (Table 3): Compared to territorial males, nonterritorial fish grazed significantly less $(p<0.001)$, but regardless of social status $B$ morph fish grazed significantly less than $W$ morph fish ( $p<0.001$; Figure 2c).

\subsection{Field observations of aggressive interactions}

Overall, the morph of an M. callainos territorial intruder has a significant effect on the amount of aggression received from territorial focal fish ( $p<0.001-T a b l e ~ 4$ model ii): B morph intruders receiving more aggression than their $\mathrm{W}$ morph counterparts. However, there is also a significant interaction between focal and intruder morph type ( $p=0.026-$ Table 4 model i) and aggression bias appears to differ between the morphs: $\mathrm{B}$ morph intruders receive significantly more aggression from $\mathrm{B}$ morph territory holders than $\mathrm{W}$ morph intruders do ( $p<0.001-T a b l e ~ 4$ model iii), whereas B and W morph intruders do not differ significantly in the amount of aggression received from territorial W morph males ( $p=0.332-$ Table 4 model iv; Figure 3a). Although on average B morph territorial males received more aggression than $\mathrm{W}$ morph males from heterospecifics this difference is not significant ( $p=0.068-T a b l e ~ 4$, model v; Figure 3c).

\section{3 | Laboratory aggression trials}

\subsubsection{Differences in focal fish behaviour between species(/experiment), populations and sexes}

The analysis of all data from the laboratory aggression experiments indicated that species had a significant effect on the overall level of aggression displayed (i.e. total aggression count to both stimulus fish): M. callainos were more aggressive than M. zebra, but sex had no significant effect on the level of aggression (Species $p=0.002$; Sex $p=0.963-$ Table 5 model i). To test whether this difference in aggressiveness was a real difference between species, or due to M. callainos being presented more often with the possibility of being aggressive towards conspecific fish in these experiments, a subset of M. zebra $\mathrm{CB}$ and M. callainos males from the three experiments was compared (Table 5 model ii): M. zebra displayed a significantly $(p=0.001)$ higher level of aggression in the experiment where the stimulus pair consisted of one conspecific and one heterospecific (Exp. 1) compared to 
TABLE 4 Descriptive statistics and generalized linear model results for observations of aggression biases by and towards Maylandia callainos morphs (B, blue; $W$, white) in the field. Roman numerals correspond to those given methods (Table 1c)

\begin{tabular}{|c|c|c|c|c|c|c|}
\hline Model & $\begin{array}{l}\text { Response } \\
\text { variable }\end{array}$ & $\begin{array}{l}\text { Fixed effects } \\
\text { (and means) }\end{array}$ & Estimate & SE & $z$-value & $p$-value \\
\hline \multicolumn{7}{|c|}{$\begin{array}{l}\text { i) All focal fish. } \mathrm{N} \text { obs }=36 . \text { Residual } d f=31 . \text { Random effect variance }=0 \text {. Dispersion } \\
\text { ratio }=1.16 . \mathrm{AIC}=79.1\end{array}$} \\
\hline & $\begin{array}{l}\text { Aggression } \\
\text { count }\end{array}$ & $\begin{array}{l}\text { Intercept } \\
\text { Focal morph } \\
\qquad(B=1.6, \\
W=1.1) \\
\text { Intruder morph } \\
\quad(B=1.9, \\
W=0.8) \\
\text { Focal }{ }^{*} \text { Intruder } \\
\quad(B-B=2.6, \\
B-W=0.7, \\
W-B=1.2, \\
W-W=0.9)\end{array}$ & $\begin{array}{l}1.34 \\
-1.03 \\
-2.69 \\
2.05\end{array}$ & $\begin{array}{l}0.46 \\
0.65 \\
0.65 \\
0.92\end{array}$ & $\begin{array}{l}2.93 \\
-1.57 \\
-4.15 \\
2.22\end{array}$ & $\begin{array}{l}0.003 \\
0.116 \\
<0.001 \\
0.026\end{array}$ \\
\hline
\end{tabular}

ii) All focal fish. $\mathrm{N}$ obs $=36$. Residual $d f=33$. Random effect variance $=0$. Dispersion ratio $=1.21 . \mathrm{AIC}=80.1$

$\begin{array}{clllll}\text { Aggression } & \text { Intercept } & 0.89 & 0.32 & 2.79 & 0.005 \\ \text { count } & \text { Intruder morph } & -1.78 & 0.45 & -3.95 & <0.001 \\ & (B=1.9 & & & & \\ & W=0.8) & & & & \end{array}$

iii) $\mathrm{B}$ focal fish. $\mathrm{N}$ obs $=18$. Residual $d f=15$. Random effect variance $=0$. Dispersion ratio $=1.29$

$\begin{array}{clllll}\text { Aggression } & \text { Intercept } & 1.34 & 0.46 & 2.93 & 0.003 \\ \text { count } & \text { Intruder morph } & -2.69 & 0.65 & -4.15 & <0.001 \\ & (B=2.6 & & & & \\ & W=0.7) & & & & \end{array}$

iv) $\mathrm{W}$ focal fish. $\mathrm{N}$ obs $=18$. Residual $d f=15$. Random effect variance $=0$. Dispersion ratio $=1.29$

$\begin{array}{clllll}\text { Aggression } & \text { Intercept } & 0.32 & 0.47 & 0.69 & 0.493 \\ \text { count } & \text { Intruder morph } & -0.64 & 0.66 & -0.97 & 0.332 \\ & (B=1.2, & & & & \\ & W=0.9) & & & & \end{array}$

v) Heterospecific aggressors. $d f=17$. Dispersion ratio $=1.39$

$\begin{array}{clllll}\text { Aggression } & \text { Intercept } & 0.58 & 0.25 & 2.30 & 0.021 \\ \text { count } & \text { Focal morph } & -0.83 & 0.45 & -1.82 & 0.068 \\ & (B=1.8 & & & & \\ & W=0.8) & & & & \end{array}$

Abbreviations: $\mathrm{N}$ obs, number of observations; Residual $d f$, residual degrees of freedom; SE, standard error (Figure 3a,c). the experiment where they were presented with two heterospecific stimulus fish (Exp. 3). There was no significant difference ( $p=0.782$ ), however, in the level of aggression between the species in the experiments in which the stimulus pairs contained one conspecific (Exp. 1: M. zebra focal fish) or two conspecifics (Exp. 2: M. callainos focal fish) stimulus fish. This suggests that the presence or absence of a conspecific stimulus fish contributed to the overall difference in the level of aggression observed between the species in these experiments. There is therefore no evidence here of differences in intrinsic level of aggression between these species, rather that aggression among heterospecifics is lower than among conspecifics.

Species did not have a significant effect on the proportion of attacks:displays, but sex did. On average females attack more than they display, whereas males perform roughly equal proportions of attacks and displays (Species $p=0.091$; Sex $p<0.001-T a b l e ~ 5$ model iii).
Maylandia zebra population had a significant effect on the level of aggression displayed: sympatric Thumbi West (TW) fish, were significantly more aggressive to the heterospecific stimuli fish overall than those from the allopatric population at Chiofu Bay (CB), sex did not have a significant effect (populations CB-NB $p=0.206$, CB-TW $p<0.001$; $\operatorname{sex} p=0.296-$ Table 5 model iv).

\subsubsection{Aggression biases in pairwise intruder choice tests}

Experiment 1: As expected, M. zebra stimulus fish received more aggression than M. callainos stimulus fish from M. zebra focal fish-that is, M. zebra focal fish showed a significant conspecific aggression bias ( $p<0.001-$ Table 6 model i). 


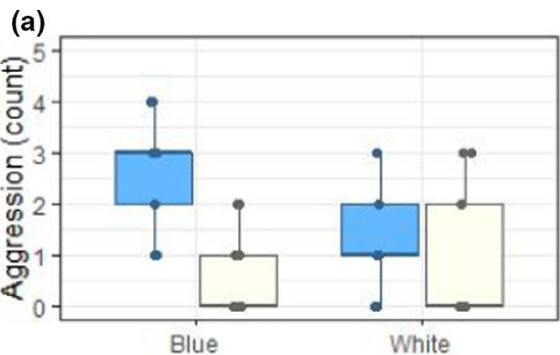

(c)

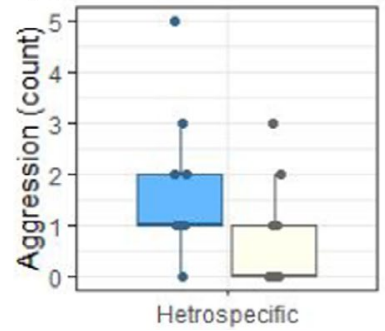

(b)

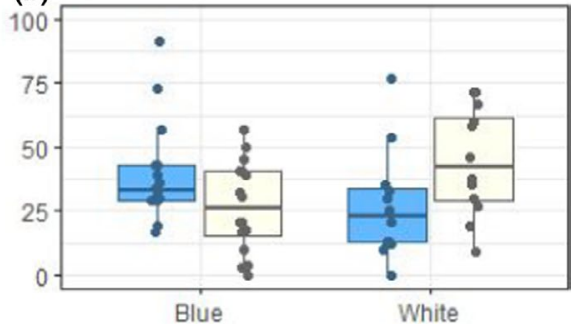

(e)

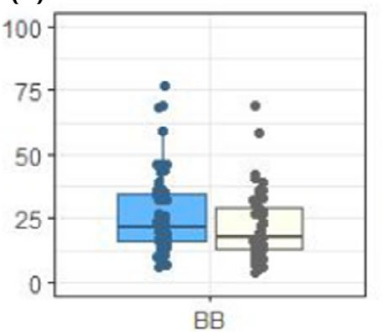

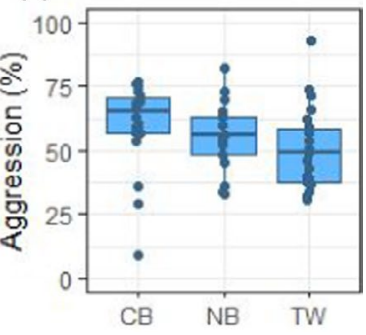

FIGURE 3 Conspecific and heterospecific aggression biases in the field and lab. Bar colour = colour of Maylandia callainos fish receiving aggression (blue $=$ blue morph, white $=$ white morph), $x$-axis $=$ aggressor. (a) In the field, $\mathrm{B}$ morph territorial intruders receive more conspecific aggression than their W morph counterparts, but only B morph focal fish showed a significant aggression bias towards other B morph fish (Table 4). (b) In laboratory experiments (Exp 2) focal fish showed a significant own morph aggression bias (Table 6). (c) There is no significant difference in the amount of aggression territorial B \& W morph fish received from heterospecifics in the field (Table 4). (d) In the lab, B morph stimulus fish received significantly more aggression from heterospecific M. zebra than W morph stimulus fish (Table 6). (e) M. zebra populations differ in the strength of aggression bias towards the common M. callainos morph. There is no significant difference between Chiofu Bay (CB) \& Nkhata Bay (NB), but fish from Thumbi West (TW) show a significantly weaker B morph aggression bias than fish from CB (Table 6)

TAB LE 5 Descriptive statistics and generalized linear model results for differences in total aggression displayed by the different species, populations and sexes in laboratory aggression trials

\begin{tabular}{|c|c|c|c|c|c|c|c|c|}
\hline Model & $\begin{array}{l}\text { Response } \\
\text { variable }\end{array}$ & Fixed factor (and means) & $d f$ & Estimate & SE & Statistic & $p$-value & $\mathrm{DR}$ \\
\hline i) & Aggression count & $\begin{array}{l}\text { Intercept } \\
\text { Species (M.cal = 68, } \\
\quad \text { M.zeb }=51) \\
\text { Sex }(\text { female }=57, \text { male }=55)\end{array}$ & 101 & $\begin{array}{l}4.22 \\
-0.29 \\
0.00\end{array}$ & $\begin{array}{l}0.09 \\
0.10 \\
0.09\end{array}$ & $\begin{array}{l}z=46.67 \\
-3.06 \\
0.05\end{array}$ & $\begin{array}{l}<0.001 \\
0.002 \\
0.963\end{array}$ & 5.9 \\
\hline ii) & Aggression count & $\begin{array}{l}\text { Intercept } \\
\text { Exp } 1 \text { (M.zeb = 71): Exp } 2 \\
\quad(\text { M.cal = 67 } \\
\text { : Exp } 3(\text { M.zeb = 36) }\end{array}$ & 34 & $\begin{array}{l}4.26 \\
-0.05 \\
-0.69\end{array}$ & $\begin{array}{l}0.13 \\
0.17 \\
0.17\end{array}$ & $\begin{array}{l}z=33.86 \\
0.28 \\
-3.95\end{array}$ & $\begin{array}{l}<0.001 \\
0.782 \\
0.001\end{array}$ & 6.9 \\
\hline iii) & Attack:Display & $\begin{array}{l}\text { Intercept } \\
\text { Species (M.cal = 35:33, } \\
\text { M.zeb }=28: 22) \\
\text { Sex (female }=35: 24 \text {, } \\
\quad \text { male }=26: 27)\end{array}$ & 91 & $\begin{array}{l}0.27 \\
0.18 \\
-0.43\end{array}$ & $\begin{array}{l}0.10 \\
0.11 \\
0.10\end{array}$ & $\begin{array}{l}t=2.79 \\
1.71 \\
-4.16\end{array}$ & $\begin{array}{l}0.006 \\
0.091 \\
<0.001\end{array}$ & 3.3 \\
\hline
\end{tabular}

Note: Roman numerals correspond to those given in methods (Table 1d).

Abbreviations: CB, Chiofu Bay; df, degrees of freedom; DR, dispersion ratio; M.cal, M. callainos; M.zeb, M. zebra; NB, Nkhata Bay; SE, standard error; TW, Thumbi West Island.

Experiment 2: Within M. callainos, sex had no effect on aggression count, but there was a significant interaction between morph of focal and stimulus fish (Interaction $p=0.002$; Sex $p=1.000-$ Table 6 model ii). To further clarify whether the difference in the proportion of aggression directed to stimulus fish of each colour morph is due to an own morph aggression bias (i.e. each colour morph is more 
TAB LE 6 Descriptive statistics and quasibinomial generalized linear model results for aggression biases displayed in pairwise intruder choice tests in the laboratory

\begin{tabular}{|c|c|c|c|c|c|c|c|}
\hline Model & Response variable & Fixed factor (and means) & $d f$ & Estimate & SE & $t$-value & $p$-value \\
\hline i) & Aggression count & $\begin{array}{l}\text { Intercept } \\
\text { Stimulus morph }(B B=55 \text {, } \\
\qquad B=16)\end{array}$ & 19 & $\begin{array}{l}1.21 \\
-2.41\end{array}$ & $\begin{array}{l}0.19 \\
0.27\end{array}$ & $\begin{array}{l}6.31 \\
-8.92\end{array}$ & $\begin{array}{l}<0.001 \\
<0.001\end{array}$ \\
\hline \multicolumn{8}{|c|}{ Exp 2; B\&W focal fish, conspecific stimulus fish } \\
\hline \multicolumn{8}{|c|}{ Exp 3; BB focal fish, heterospecific stimulus fish } \\
\hline iv) & Aggression count & $\begin{array}{l}\text { Intercept } \\
\text { Stimulus morph }(B=27 \text {, } \\
\qquad W=21) \\
\text { Sex (female }=25, \text { male }=23 \text { ) }\end{array}$ & 127 & $\begin{array}{l}0.21 \\
-0.42 \\
0.00\end{array}$ & $\begin{array}{l}0.11 \\
0.12 \\
0.12\end{array}$ & $\begin{array}{l}1.98 \\
-3.52 \\
0.00\end{array}$ & $\begin{array}{l}0.050 \\
<0.001 \\
1.000\end{array}$ \\
\hline v) & $\begin{array}{l}\text { Aggression count } \\
\text { to } \mathrm{B}: \mathrm{W}\end{array}$ & $\begin{array}{l}\text { Intercept } \\
\text { Population (CB }=24: 16 \text {, } \\
\quad \text { NB = 26:20 } \\
\text { TW }=30: 29) \\
\text { Sex (female }=27: 24 \\
\quad \text { male }=26: 19)\end{array}$ & 63 & $\begin{array}{l}0.32 \\
-0.19 \\
-0.40 \\
0.22\end{array}$ & $\begin{array}{l}0.17 \\
0.23 \\
0.20 \\
0.17\end{array}$ & $\begin{array}{l}1.89 \\
-0.85 \\
-2.03 \\
1.30\end{array}$ & $\begin{array}{l}0.064 \\
0.400 \\
0.047 \\
0.200\end{array}$ \\
\hline
\end{tabular}

Note: Roman numerals correspond to those given in methods (Table 1e).

Abbreviations: B, blue morph; W, white morph (Maylandia callainos); BB, blue/black/barred morph (M. zebra); CB, Chiofu Bay; NB, Nkhata Bay; TW, Thumbi West Island; $d f$, degrees of freedom, SE, standard error (Figure 3b,d,e).

aggressive to other fish of the same colour) or an overall common morph aggression bias (i.e. fish of both colour morphs direct more aggression towards common/blue morph fish), stimulus type was recoded from blue/white to other/own and common/rare: Ownmorph stimulus fish received significantly more aggression than other-morph fish, whereas whether the stimulus was common or rare had no significant effect (own/other $p=0.001$; common/rare $p=0.667-$ Table 6 model iii, Figure 3b).

Experiment 3: M. callainos B-morph stimulus fish received significantly more aggression than $\mathrm{W}$-morph fish from heterospecific M. zebra focal fish, and sex had no effect on this bias (stimulus morph $p<0.001$; sex $p=1.000-$ Table 6 model iv, Figure 3d). The strength of aggression bias (proportion of aggression to B morph) differs between M. zebra populations: TW focal fish displayed a significantly lower proportion of aggression towards the blue morph than those from $C B$ (i.e. a weaker bias), there was no difference between NB and CB and sex had no significant effect (population CB-TW $p=0.047$, CB-NB $p=0.400$; sex $p=0.200-$ Table 6 model v; Figure 3e).

\section{DISCUSSION}

Our field observations of M. callainos, a polychromatic mbuna cichlid from Lake Malawi, indicated that common (blue) morph territorial intruders received more aggression than rare (white) morph intruders. Pairwise intruder choice tests in a controlled laboratory setting demonstrated that males and females of each morph bias aggression towards their own morph. These results add to the evidence that inherent own-morph aggression biases, which result in negative frequency-dependent selection on rare colour morphs, can contribute to balancing selection and thereby promote the maintenance of polychromatism (Dijkstra et al., 2008; Lehtonen, 2014; Scali et al., 2020). As there is little possibility for imprinting in these fish, and it seems unlikely that they can see their own colour, such an ownmorph bias is likely the result of an inherent (genetically determined) behavioural/preference polymorphism.

While this and previous studies (e.g. Dijkstra et al., 2008; Dijkstra, Hemelrijk, et al., 2009; Lehtonen, 2014; Scali et al., 2020; Seehausen \& Schluter, 2004) have shown that aggression biases can 
be involved in stabilizing polychromatism, to our knowledge this is the first study to identify benefits to rare morph cichlids which may result from receiving less aggression in the natural environment. We found there to be significantly more territory holding rare morph males than would be expected given the proportions of the two colours in the general population. Our observations suggest that the over-representation of rare morph territory owners may be influenced by two factors. First, different morph males appear to have higher tolerance of each other as neighbours, being found on average significantly closer to each other than same morph males. Additionally, the smallest average distance was found to be between white and blue males. Second, both territorial and nonterritorial white morph individuals spend more time feeding, which suggests that the rare colour morph may benefit from lack of recognition during competition for non-mating related resources (Dijkstra et al., 2008; Lehtonen, 2014; Pérez i de Lanuza et al., 2017; Scali et al., 2020).

Further to showing that rare morph individuals can benefit from reduced intraspecific aggression, we found that a closely related ecologically similar heterospecific (M. zebra) also biases aggression towards the $M$. callainos blue morph. While these results are in conflict with those from another cichlid fish system, which suggest that rare morphs may be disadvantaged by greater heterospecific aggression (Lehtonen et al., 2015), given that aggression among heterospecifics is often higher among more similar coloured than more differently coloured species (Anderson \& Grether, 2010; Genner et al., 1999; Losin et al., 2016; Pauers et al., 2008), it is not surprising to find that in some cases rare morph individuals may receives less aggression from a heterospecific which is more similar in colour to the common morph.

There was no difference in the total aggression displayed by males and females, nor in the aggression biases observed. There was however a difference in the number of attacks and displays used. We speculate that the greater use of direct attacks compared to display behaviours by females (this study and Arnott \& Elwood, 2009) may be due to the difference in competition among females and males (i.e. greater use of attack behaviours may be more beneficial than displays when trying to win or defend caves among the rocks which are desirable shelters for mouthbrooding females).

In cichlids and other taxa, laboratory studies have shown that in species which differ in colour among allopatric populations, males tend to bias aggression towards males from their own population (Bolnick et al., 2016; Cooke \& Turner, 2018; Tyers \& Turner, 2013; Yang et al., 2018). In this study, we found that heterospecific aggression also varies depending on whether a pair of species occurs in sympatry or allopatry. The level of aggression (total aggression count to both $M$. callainos morphs) differs between M. zebra populations: M. zebra from Thumbi West (TW), which cooccur with high numbers of $M$. callainos, were significantly more aggressive to M. callainos than those from Chiofu Bay (CB), which are naïve to $M$. callainos. M. zebra from Nkhata Bay (NB), which co-occur with lower numbers of M. callainos showed and intermediate level of aggression. These findings support the hypothesis that aggression among heterospecifics may often not simply be due to misdirected aggression among species (Peiman \& Robinson, 2010), which would be indicated by higher levels of aggression from the allopatric M. zebra population (CB). The persistence of heterospecific aggression at NB support the idea that it has an adaptive function in long-term co-existing multi-species communities (Losin et al., 2016; Peiman \& Robinson, 2010). Although there are no M. callainos at Chiofu Bay, this location is home to another closely-related species (M. esterae) which has blue males, and brown, orange and orange blotch females. M. zebra at Chiofu Bay therefore do co-occur with a similar blue morph fish, but no white morph fish and we found that the M. zebra from this location has a stronger blue-morph aggression bias than the other M. zebra populations which co-occur with blue and white $M$. callainos. A previous study of a polymorphic frog species found stronger aggression biases among morphs when they occur in allopatry compared to when they are found in sympatry (Yang et al., 2018). Our results show a similar pattern in heterospecific aggression; a weaker blue morph aggression bias in M. zebra populations which coexist with both colour morphs.

Our results indicate that a rare colour morph may benefit from lack of recognition as a resource competitor, by both conspecifics and heterospecifics. This results in rare morph individuals receiving less aggression and gaining improved access to territories and food. This can benefit rare morph individuals while they are rare, but then what prevents them from increasing in frequency until fixation? Firstly, we found that rare (white) morph individuals were more aggressive towards their own morph than they were to the common (blue) morph, which would result in white morph individuals experiencing increasing levels of aggression as they became more common. Secondly, the lower level of heterospecific aggression bias towards the common morph, in populations with blue and white morphs, suggests that heterospecifics learn or evolve the ability to recognize rare morph individuals as competitors. The ability to recognize rare morph individuals may increase as they become more common: TW has the highest frequency of white morph individuals and the weakest common morph aggression bias by heterospecifics. Finally, female preference for common-morph males may result in a disadvantage to rare morph males (Roberts et al., 2009). The genes responsible for the expression of the melanin-disrupted ('blotched') morphs are almost always closely linked to a dominant female determiner, and so are generally much more common in females. This suggests that these colour phenotypes are disadvantageous to males, although they may be advantageous to females by providing increased crypsis or reduced aggression from conspecifics and/or heterospecifics. The reason for the differences in the types of rare morphs and frequency of rare morph individuals in different populations remains unclear but is likely due to multiple factors. Further investigation of differences in aggression biases and rare morph advantages in different mbuna communities, along with a detailed study of differences in morph crypsis and predation pressure in different populations/environments would greatly increase our understanding of the variation in polychromatism in these fish. 


\section{5 | CONCLUSIONS}

Our results support previous studies indicating that negative frequency-dependent antagonism can be generated by own-morph aggression biases among conspecifics in cichlids which display polychromatism. We find that heterospecifics show reduced aggression to rare morph individuals, suggesting that heterospecific aggression may also facilitate invasion of rare colour morphs into a population. We identify potential advantages to rare morph individuals in the field, in terms of territory and foraging.

\section{ACKNOWLEDGEMENTS}

This work was supported by Bangor University PhD scholarships to AMT and GMC. The authors thank Aaron Scott, Winnie Courtene-Jones, Beth Powell for help with field recording and James Whitman for collecting live fish. Additionally, the authors thank the Department for National Parks and Wildlife in Malawi for allowing us to collect fish from Lake Malawi National Park. All behavioural experiments were approved by Bangor University ethical review. Finally, the authors thank P.D. Dijkstra, Samuel Lymbery and two other anonymous reviewers for comments on versions of this manuscript.

\section{CONFLICT OF INTEREST}

The authors have no conflict of interest to declare.

\section{AUTHOR CONTRIBUTION}

Alexandra M. Tyers carried out all data analysis and laboratory experiments. Alexandra M. Tyers/Gavan M. Cooke/George F. Turner contributed to collection of field data and fish. Alexandra M. Tyers/ George F. Turner drafted the manuscript.

\section{DATA AVAILABILITY STATEMENT}

The data that support the findings of this study can be viewed at https://doi.org/10.5061/dryad.0gb5mkm21.

\section{PEER REVIEW}

The peer review history for this article is available at https://publo ns.com/publon/10.1111/jeb.13929.

\section{ORCID}

Alexandra M. Tyers (D) https://orcid.org/0000-0002-1153-1347

\section{REFERENCES}

Anderson, C. N., \& Grether, G. F. (2010). Interspecific aggression and character displacement of competitor recognition in Hetaerina damselflies. Proceedings of the Royal Society of London B: Biological Sciences, 277, 549-555. https://doi.org/10.1098/rspb.2009.1371

Arnott, G., \& Elwood, R. W. (2009). Gender differences in aggressive behaviour in convict cichlids. Animal Behaviour, 78, 1221-1227. https://doi.org/10.1016/j.anbehav.2009.08.005

Bolnick, D. I., Hendrix, K., Jordan, L. A., Veen, T., \& Brock, D. (2016). Intruder colour and light environment jointly determine how nesting male stickleback respond to simulated territorial intrusions. Biology Letters, 12, 20160467. https://doi.org/10.1098/rsbl.2016.0467
Cooke, G. M., \& Turner, G. F. (2018). Team colours matter when playing away from home: Aggression biases in geographically isolated mbuna cichlid populations. Hydrobiologia, 809, 31-40. https://doi. org/10.1007/s10750-017-3442-6

Couldridge, V. C. K., \& Alexander, G. J. (2002). Colour patterns and species recognition in four closely related species of Lake Malawi cichlid. Behavioral Ecology, 13, 59-64. https://doi.org/10.1093/behec o/13.1.59

Dijkstra, P. D., Hemelrijk, C. K., Seehausen, O., \& Groothuis, T. G. G. (2009a). Colour polymorphism and intrasexual selection in assemblages of cichlid fish. Behavioural Ecology, 20, 138-144. https://doi. org/10.1093/beheco/arn125

Dijkstra, P. D., Seehausen, O., \& Groothuis, T. G. G. (2008). Intrasexual competition among females and the stabilization of a conspicuous colour polymorphism in a Lake Victoria cichlid fish. Proceedings of the Royal Society of London B: Biological Sciences, 275, 519-526. https://doi.org/10.1098/rspb.2007.1441

Dijkstra, P. D., Seehausen, O., Pierotti, M. E. R., \& Groothuis, T. G. G. (2007). Male-male competition and speciation: Aggression bias towards differently coloured rivals varies between stages of speciation in a Lake Victoria cichlid species complex. Journal of Evolutionary Biology, 20, 496-502. https://doi.org/10.1111/j.1420-9101.2006.01266.x

Dijkstra, P. D., van Dijk, S., Groothuis, T. G. G., Pierotti, M. E. R., \& Seehausen, O. (2009). Behavioral dominance between female color morphs of a Lake Victoria cichlid fish. Behavioral Ecology, 20, 593600. https://doi.org/10.1093/beheco/arp036

Drury, J. P., Cowen, M. C., \& Grether, G. F. (2020). Competition and hybridization drive interspecific territoriality in birds. Proceedings of the National Academy of Sciences of the United States of America, 117, 12923-12930. https://doi.org/10.1073/pnas.1921380117

Genner, M. J., Turner, G. F., \& Hawkins, S. J. (1999). Resource control by territorial male cichlids in Lake Malawi. Journal of Animal Ecology, 68, 522-529. https://doi.org/10.1111/(ISSN)1365-2656

Grether, G. F., Losin, N., Anderson, C. N., \& Okamoto, K. (2009). The role of interspecific interference competition in character displacement and the evolution of competitor recognition. Biological Reviews, 84, 617-635. https://doi.org/10.1111/j.1469-185X.2009.00089.x

Henze, M. J., Lind, O., Mappes, J., Rojas, B., \& Kelber, A. (2018). An aposematic colour-polymorphic moth seen through the eyes of conspecifics and predators - Sensitivity and colour discrimination in a tiger moth. Functional Ecology, 32, 1797-1890. https://doi. org/10.1111/1365-2435.13100

Hughes, K. A., Houde, A. E., Price, A. C., \& Rodd, F. H. (2013). Mating advantage for rare males in wild guppy populations. Nature, 503 108-110. https://doi.org/10.1038/nature12717

Huxley, J. (1955). Morphism and evolution. Heredity, 9, 1-52. https://doi. org/10.1038/hdy.1955.1

Jordan, R. C. (2008). Color-based association among heterospecifics in Lake Malawi rock-dwelling cichlids. Ethology, 114, 272-278. https:// doi.org/10.1111/j.1439-0310.2007.01460.x

Kim, K. W., Jackson, B. C., Zhang, H., Toews, D. P. L., Taylor, S. A., Greig, E. I., Lovette, I. J., Liu, M. M., Davison, A., Griffith, S. C., Zeng, K. \& Burke, T. (2019). Genetics and evidence for balancing selection of a sex-linked colour polymorphism in a songbird. Nature Communications, 10, 1852-1861. https://doi.org/10.1038/s4146 7-019-09806-6

Konings, A. (2007). Malawi cichlids in their natural habitat (4th ed.). Cichlid Press.

Lande, R., Seehausen, O., \& van Alphen, J. J. M. (2001). Mechanisms of rapid sympatric speciation by sex reversal and sexual selection in cichlid fish. Genetica, 112-113, 435-443.

Lehtonen, T. K. (2014). Colour biases in territorial aggression in a Neotropical cichlid. Oecologia, 175, 85-93. https://doi.org/10.1007/ s00442-013-2879-1

Lehtonen, T. K., Sowersby, W., \& Wong, B. B. M. (2015). Heterospecific aggression bias towards a rare colour morph. Proceedings of the 
Royal Society of London B: Biological Sciences, 282, 20151551. https://doi.org/10.1098/rspb.2015.1551

Losin, N., Drury, J. P., Peiman, K. S., Storch, C., \& Grether, G. F. (2016). The ecological and evolutionary stability of interspecific territoriality. Ecology Letters, 19, 260-267. https://doi.org/10.1111/ele.12561

Maan, M. E., Eshuis, B., Haesler, M. P., Schneider, M. V., van Alphen, J. J. M., \& Seehausen, O. (2008). Color polymorphism and predation in a Lake Victoria cichlid fish. Copeia, 3, 621-629. https://doi. org/10.1643/CE-07-114

Maan, M. E., \& Sefc, K. M. (2013). Colour variation in cichlid fish: Developmental mechanisms, selective pressures and evolutionary consequences. Seminars in Cell \& Developmental Biology, 24, 526528. https://doi.org/10.1016/j.semcdb.2013.05.003

Pauers, M. J., Kapfer, J. M., Fendos, C. E., \& Berg, C. S. (2008). Aggressive biases towards similarly coloured males in Lake Malawi cichlid fishes. Biology Letters, 4, 156-159. https://doi.org/10.1098/ rsbl.2007.0581

Peiman, K. S., \& Robinson, B. W. (2010). Ecology and evolution of resource-related heterospecific aggression. The Quarterly Review of Biology, 85, 133-158. https://doi.org/10.1086/652374

Pérez i de Lanuza, G., Carretero, M. A., \& Font, E. (2017). Intensity of male-male competition predicts morph diversity in a color polymorphic lizard. Evolution, 71, 1832-1840. https://doi.org/10.1111/ evo.13256

Ribbink, A. J., Marsh, B. A., Marsh, A. C., Ribbink, A. C., \& Sharp, B. J. (1983). A preliminary survey of the cichlid fishes of rocky habitats in Lake Malawi. South African Journal of Zoology, 18, 149-308. https:// doi.org/10.1080/02541858.1983.11447831

Roberts, R. B., Ser, J. R., \& Kocher, T. D. (2009). Sexual conflict resolved by invasion of a novel sex determiner in Lake Malawi cichlid fishes. Science, 326, 998-1001. https://doi.org/10.1126/science.1174705

RStudio Team. (2019). RStudio: Integrated development for R. Rstudio. PBC. http://www.rstudio.com/

Scali, S., Mangiacotti, M., Sacchi, R., Coladonato, A. J., Falaschi, M., Saviano, L., Rampoldi, M. G., Crozi, M., Perotti, C., Zucca, F., Gozzo, E., \& Zuffi, M. A. L. (2020). Close encounters of the three morphs: Does color affect aggression in a polymorphic lizard? bioRxiv. https://doi.org/10.1101/2020.05.02.074146

Seehausen, O., \& Schluter, D. (2004). Male-male competition and nuptial-colour displacement as a diversifying force in Lake Victoria cichlid fishes. Proceedings of the Royal Society of London B: Biological Sciences, 271, 1345-1353. https://doi.org/10.1098/ rspb.2004.2737

Seehausen, O., \& van Alphen, J. J. M. (1998). The effect of male coloration on female mate choice in closely related Lake Victoria cichlids (Haplochromis nyererei complex). Behavioral Ecology and Sociobiology, 42, 1-8. https://doi.org/10.1007/s002650050405
Seehausen, O., van Alphen, J. J. M., \& Lande, R. (1999). Color polymorphism and sex ratio distortion in a cichlid fish as an incipient stage in sympatric speciation by sexual selection. Ecology Letters, 2, 367378. https://doi.org/10.1046/j.1461-0248.1999.00098.x

Streelman, J.T.,Albertson, R.C., \& Kocher, T.D. (2003). Genome mapping of the orange blotch colour pattern in cichlid fish. Molecular Ecology, 12 2465-2471. https://doi.org/10.1046/j.1365-294x.2003.01920.x

Surmacki, A., Ożarowska-Nowicka, A., \& Rosin, Z. M. (2013). Color polymorphism in a land snail Cepaea nemoralis (Pulmonata: Helicidae) as viewed by potential avian predators. Naturwissenschaften, 100, 533-540. https://doi.org/10.1007/s00114-013-1049-y

Svensson, E. I. (2017). Back to basics: Using colour polymorphisms to study evolutionary processes. Molecular Ecology, 26, 2204-2211. https://doi.org/10.1111/mec.14025

Takahashi, Y., Yoshimura, J., Morita, S., \& Watanabe, M. (2010). Negative frequency-dependent selection in female colour polymorphism of a damselfly. Evolution, 64, 3620-3628. https://doi. $\operatorname{org} / 10.1111 / \mathrm{j} .1558-5646.2010 .01083 . x$

Tyers, A. M., \& Turner, G. F. (2013). Signal and preference divergence among populations of the non-endemic basal Lake Malawi cichlid fish Astatotilapia calliptera (Perciformes: Cichlidae). Biological Journal of the Linnean Society, 110, 180-188. https://doi.org/10.1111/ bij.12105

Wellenreuther, M., Svensson, E. I., \& Hansson, B. (2014). Sexual selection and genetic colour polymorphisms in animals. Molecular Ecology, 23, 5398-5414. https://doi.org/10.1111/mec.12935

Yang, Y., Dugas, M. B., Sudekum, H. J., Murphy, S. N., \& Richards-Zawacki, C. L. (2018). Male-male aggression is unlikely to stabilize a poison frog polymorphism. Journal of Evolutionary Biology, 31, 457-468. https://doi.org/10.1111/jeb.13243

\section{SUPPORTING INFORMATION}

Additional supporting information may be found in the online version of the article at the publisher's website.

How to cite this article: Tyers, A. M., Cooke, G. M., \& Turner, G. F. (2021). Rare morph Lake Malawi mbuna cichlids benefit from reduced aggression from con- and hetero-specifics. Journal of Evolutionary Biology, 34, 1678-1690. https://doi. org/10.1111/jeb.13929 